\title{
Series Editors' Preface
}

The fourth tranche of the Companions series marks in its own way the underlying themes of the series as whole: Scottish literature is multivalent, multilingual and vibrant. Each volume also reflects the series ethos: to challenge, set new perspectives and work towards defining differences of canon in Scottish literature. Such definition of difference must always be sensitive and each volume in the 2012 tranche shows not only the confidence of upto-date, leading-edge scholarship, but the flexibility of nuanced thought that has developed in Scottish literary studies in recent years. A tranche which balances a volume on women's writing with volumes on two major male writers subverts, even on the most superficial reading, any version of an older tradition which depended on a canon based on 'great' writers, mostly, if not exclusively, male. In approaching Scott and Hogg contributors have demonstrated fresh thinking and re-contextualised their work, opening them to new insights and enjoyment, while the authors in the volume on Women's Writing reinterpret and re-organise the very structures of thought through which we experience the writing explored.

Scott, often in the past taken to represent a stuffy old-fashioned male-dominated literary canon, is revisited, reassessed and brought to our minds anew. One is reminded of the remark of the great European scholar Martin Esslin to one of the series editors that Scott was the greatest artist in any artform of the nineteenth century. Such a statement may embody the generalising attitudes of an older generation, but Esslin's argument was based not just on Scott's range and innovations, but on the importance of his influence on his successors, not just in literature but in other arts. Hogg meantime has often previously suffered by comparison with Scott, misunderstood and misread in ways the Hogg volume makes clear as it demystifies past perceptions and opens new vistas on his work's scope. The Scottish Women's Writing volume completes a trio of innovative Companions in its range of disparate viewpoints. Avoiding easy categories or theories, these demonstrate with rigour and vigour that, though in some genres, like drama, women's writing has had a difficult time historically, it has, not least in the Gaelic tradition, always played a crucial 
role. The volume rightly and lucidly interrogates any system of classification that obscures this insight. The 2012 tranche as a whole continues the Companions series project of reviewing and renewing the way we read and enjoy the rich diversity of Scottish literature

Ian Brown

Thomas Owen Clancy 